\section{Dikegulac-sodium Spray Enhances Uniform Regrowth of Murraya paniculata (L.) Jack Hedge}

\author{
Osamu Kawabata and Richard A. Criley \\ Department of Horticulture, University of Hawaii at Manoa, Honolulu, \\ HI 96822
}

Additional index words. growth regulator, mock orange, apical dominance, woody ornamental, landscape maintenance, heterogeneity of slopes

\begin{abstract}
An aqueous solution of dikegulac-sodium at 0, 2000, 4000, 6000, or $8000 \mathrm{mg}$ a.i./ liter was sprayed on a mature Murraya paniculata hedge as the first leaves expanded on newly developing lateral shoots after trimming. The lateral shoots from each $0.09-\mathrm{m}^{2}$ hedge surface elongated less and the coefficient of variation (cv) decreased as the growth regulator concentration increased. Application of dikegulac-sodium at $4000 \mathrm{mg}$ a.i./liter to the most distal leaf on topped, single-leader seedlings inhibited the elongation of distal shoots while it enhanced proximal shoot growth. Dikegulac-sodium spray between 4000 and $6000 \mathrm{mg}$ a.i./liter to the hedge decreased apical dominance among lateral shoots and enhanced uniform regrowth without causing visible damages. The $\mathrm{CV}$ reduction was attributed to the growth regulator-induced weakening of apical dominance. Chemical name used: sodium salt of 2,3:4,6-bis- $O$-(1-methylethylidene)- $\alpha$-L-xylo-2-hexulofuranosonic acid (dikegulac-sodium).
\end{abstract}

Murraya paniculata, commonly known as mock orange in Hawaii, is a 2- to 7-m-tall ornamental shrub in the subtropical Pacific area (Neal, 1965). Although the plant is often used for hedges, its high rate of growth requires frequent trimming, making it expensive to maintain. Growth regulator use after trimming may suppress hedge growth and reduce the frequency of trimming without noticeable damage.

Dikegulac-sodium(DS) is a foliage-applied growth regulator(Bocion et al., 1975). It readily translocates to the shoot apex (Arzee et al., 1977), kills dividing cells in meristematic zone (Zilkah and Gressel, 1977), and suppresses shoot growth and weakens apical dominance (Bocion and de Silva, 1976). While the growth regulator is mainly used for pinching potted ornamentals (Sanderson, 1977; Starman, 1991), it is also used for inhibiting the growth of woody ornamentals without inducing visible damage (Cohen, 1978; de Silva et al., 1976; Sachs et al., 1975). Weakening apical dominance, a strategy for hedge growth control, is particularly desirable because it makes hedges appear full and compact (Sachs and Hackett, 1972; Sachs et al., 1970).

When a Murraya hedge was sprayed with DS after trimming (Criley, 1980), treated hedge sections appeared retarded; however, randomly sampled lateral shoots were not statistically shorter than nontreated controls. The discrep-

Received for publication 28 Apr. 1995. Accepted for publication 2 Oct. 1995. Hawaii Institute of Tropical Agriculture and Human Resources Journal Series no. 4094. The cost of publishing this paper was defrayed in part by the payment of page charges. Under postal regulations, this paper therefore must be hereby marked advertisement solely to indicate this fact. ancy could have occurred if the growth regulator differentially affected shoots of unequal size and development. While long shoots were more visible than short ones, random sampling did not allow selecting only long shoots. Although selectively sampling long, dominant shoots is common in the growth retardation studies on woody species, the degree of full and compact appearance cannot be measured by the selective sampling. An additional statistical method would be desirable for measuring the visual quality. Since the number of potential lateral shoots after trimming is predetermined at the time of spray, uniform elongation of all active lateral shoots gives an even and dense hedge. A good method of quantifying this is to use the coefficient of variation (CV) of randomly sampled shoot length.

The objectives of this research were to determine if DS sprays after trimming would suppress the elongation of Murraya lateral shoots and if they would enhance uniform regrowth of the hedge using $\mathrm{CV}$ as an indicator for the uniformity in the lateral shoot elongation.

\section{Materials and Methods}

Hedge experiment. A mature Murraya hedge located on the Univ. of Hawaii campus, Honolulu, had been maintained $1.2 \mathrm{~m}$ high, 1 $\mathrm{m}$ wide, and $20 \mathrm{~m}$ long. It was composed of two rows of plants, $0.2 \mathrm{~m}$ apart and $0.2 \mathrm{~m}$ between plants within each row. A preliminary uniformity trial indicated no significant difference in lateral shoot regrowth among individual plants. The top and side surfaces were trimmed to $10 \mathrm{~mm}$ distal to the previous trimming, and $0.3 \times 0.3-\mathrm{m}$ plots were assigned on the edges of top surface separated by $0.1-\mathrm{m}$ borders. An aqueous solution of DS at 0,2000, 4000,6000 , or $8000 \mathrm{mg}$ a.i./liter supplemented with a surfactant $(0.1 \% \mathrm{X}-77$ by volume $)$ was sprayed to runoff when the first leaves on newly elongating shoots fully expanded. A treatment set comprised the five spray concentrations randomized within neighboring plots. The treatment set was replicated on both edges of the top surface and in three hedge sections, providing six replications per treatment. The experiment was run twice: spraying the hedge on 6 May for warm- and on 24 Dec. for coolseason trials. A protective cover placed around the target plot during spraying minimized drift, and using different hedge sections in the two trials eliminated possible residual effects.

The length of newly developing lateral shoots was measured 8 weeks after spraying in two sampling methods: the longest lateral shoot emerged from the $0.3 \times 0.3-\mathrm{m}$ plot [longest shoot length (LSL)]; and nine lateral shoots located closest to the center of each of the 0.1 $\times 0.1-\mathrm{m}$ subplots [nine shoots per plot, subsampled shoot length (SSL)]. While the LSL represented only the longest shoot segment, the SSL represented the entire population, assuming that lateral shoots emerged geographically at random. Shoot length was determined from its point of attachment on the older shoot to its tip. Shoots originating $30 \mathrm{~mm}$ below the trimming level or lower were not sampled to exclude shoots that started elongation before trimming. During the regrowth periods, air minima and maxima fluctuated in ranges of 19 to $21 \mathrm{C}$ and 23 to $29 \mathrm{C}$, respectively, for warm- and 10 to $21 \mathrm{C}$ and 24 to $29 \mathrm{C}$ for cool-season trials.

The LSL and SSL were regressed on DS concentration, and the interaction with sampling methods was determined by the heterogeneity of slopes (Allen and Cady, 1982). The SSL was further grouped by size and the percent frequency distribution was graphically examined.

Seedling experiment. Six-month-old seedlings were transplanted to 1-liter plastic pots filled with a medium consisting of 1 perlite : 1 peat $(\mathrm{v} / \mathrm{v}), 7.0 \mathrm{~g} /$ pot slow-release $14 \mathrm{~N}-6.2 \mathrm{P}-$ $11.6 \mathrm{~K}$ fertilizer, and $1.0 \mathrm{~g} /$ pot minor elements (Micromax; Grace Sierra, Milpitas, Calif.), and placed under $60 \%$ plastic shade. Three months after transplanting, 16 seedlings were selected for single-stem form and uniform size. Stems were pruned at $0.5 \mathrm{~m}$ above the medium and extra leaves were removed, leaving five distal leaves on the pruned stem. The top leaf of each seedling was dipped in a DS solution of 0 or $4000 \mathrm{mg}$ a.i./liter for $3 \mathrm{sec}$ and washed with water $8 \mathrm{~h}$ later. Both treatments were replicated eight times.

The lateral shoot length, recorded 5 weeks after treatment, was regressed on the position number, 1 for the most distal to 5 for the most proximal, and the interaction with the treatments was determined by the heterogeneity of slopes. The SAS GLM procedure (SAS Institute, 1990) was used for the statistical computation for these experiments.

\section{Results and Discussion}

Hedge experiment. DS reduced lateral shoot elongation, expressed as LSL or SSL, in 
straight-line responses in the warm-season trial (warm season, Fig. 1). A significant difference was expected between means for the two sampling methods (sampling, Table 1) because of different populations each method represented. However, the interaction (concentration $\times$ sampling) also was significant, indicating the presence of two differing slopes: the negative slope for the LSL was twice as large as the slope for the SSL. In the coolseason trial, the slope of decline for the LSL was significantly larger than for the SSL again. Both regression coefficients for slopes for the cool season were larger than those for the same sampling method for warm season.

As with other shrubs that showed multiple flushes (Sachs, 1969), the Murraya LSL showed two flushes in 18 weeks after trimming in warm season. DS treatments were still effective at the 18th week as DS at 2000 to $8000 \mathrm{mg}$ a.i./liter limited the shoot length to $78 \%$ to $59 \%$ of the $0-\mathrm{mg}$ DS control's $176 \mathrm{~mm}$. Yellowing of young expanding leaves (Sachs et al., 1975) also was observed in our 8000-mg treatment in both seasons; however, affected leaves gained their normal green at maturity. Abnormal symptoms were absent on plants treated with $6000 \mathrm{mg}$ DS or less.

The frequency distribution of the SSL (Fig. 2 ) indicated the longest shoot group (>199 $\mathrm{mm}$ ) in $0 \mathrm{mg}$ DS was eliminated by any DS treatment in both seasons. In the warm season, the percentage of the shortest shoots ( 0 to 49 $\mathrm{mm}$ ) increased with the growth regulator concentration, up to $6000 \mathrm{mg} \cdot \mathrm{liter}^{-1}$, while the number of longer shoots (100 to $199 \mathrm{~mm}$ ) decreased (warm season, Fig. 2). The negative slope of the SSL in the warm season in Fig. 1 reflected this change in size distribution. In the cool season, the percentage of the shortest shoots (0 to $49 \mathrm{~mm}$ ) decreased while that of medium-sized shoots ( 50 to $99 \mathrm{~mm}$ ) increased (cool season, Fig. 2). These changes resulted in a slightly positive slope for the SSL in cool season in Fig. 1. The variation of the SSL decreased as DS concentration increased: $\mathrm{CV}$ decreased from $56 \%$ for $0 \mathrm{mg}$ to $43 \%$ for 8000 $\mathrm{mg}$ DS in the warm and from $75 \%$ to $59 \%$ in the cool season. Therefore, although DS spray did not universally inhibit lateral shoot elongation, as the SSL in the cool season slightly increased, it suppressed the occurrence of long lateral shoots (LSL) and enhanced uniform regrowth in the SSL both seasons.

Seedling experiment. Lateral shoot elongation (Fig. 3) was greatest for the most distal (position 1) shoots, and it decreased for the lower shoots in straight-line responses for 0 or $4000 \mathrm{mg}$ DS. While mean shoot lengths were not significantly different (treatment, Table 2 ), the slope for the 4000-mg DS was significantly less steep (position $\times$ treatment) than for the 0-mg DS. Consequently, two regression lines intersected each other near position 3 . As with the hedge experiment, $\mathrm{CV}$ for the 0 $\mathrm{mg}$ DS $(51 \%)$ was reduced by the $4000-\mathrm{mg}$ DS $(42 \%)$.

The negative slope for the 0-mg DS treatment demonstrated the presence of apical dominance (Martin, 1987; Phillips, 1975) among developing lateral shoots in Murraya seed-

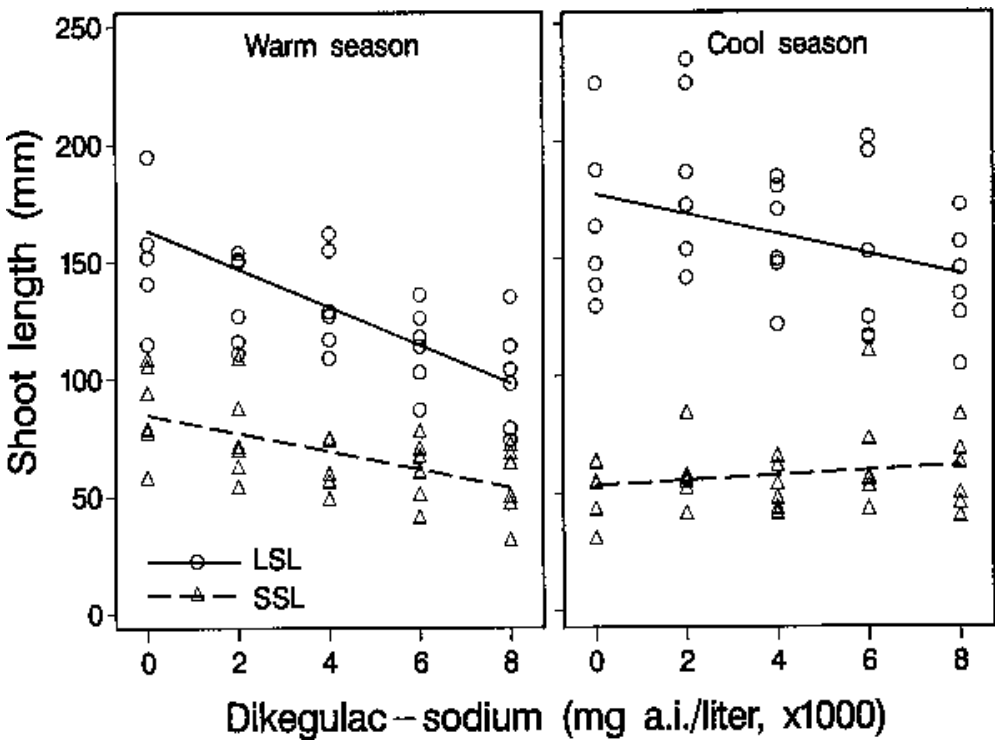

Fig. 1. Lateral shoot elongation on a Murraya paniculata hedge treated with dikegulac-sodium (DS) at 0 , $2000,4000,6000$, or $8000 \mathrm{mg}$ a.i./liter on 6 May (warm season) or 24 Dec. (cool season) as the first leaves on newly developing lateral shoots expanded after trimming. Lateral shoots were sampled 8 weeks later in two sampling methods: the longest shoot emerged from each $0.09-\mathrm{m}^{2} \mathrm{plot}$ (LSL) and the mean of nine subsampled shoots $(\mathrm{SSL})$. LSL warm season $(\mathrm{mm})=163-0.00814 \times$ DS; SSL warm season $=85-$ $0.00428 \times$ DS; LSL cool season $=179-0.00424 \times$ DS; SSL cool season $=54.6+0.00104 \times$ DS .

Table 1. Analyses of variance for regressing Murraya paniculata hedge regrowth on two sampling methods and dikegulac-sodium concentration. Dikegulac-sodium at 0,2000,4000,6000, or $8000 \mathrm{mg}$ a.i./liter was sprayed on 6 May (warm season) or 24 Dec. (cool season) as the first leaves on newly developing lateral shoots expanded after trimming. The length of the longest shoot and the mean of nine subsampled shoots emerging from $0.09-\mathrm{m}^{2}$ plot were recorded 8 weeks after treatment.

\begin{tabular}{|c|c|c|c|c|c|c|c|}
\hline \multirow[b]{2}{*}{ Source } & \multirow[b]{2}{*}{ df } & \multicolumn{3}{|c|}{ Warm season } & \multicolumn{3}{|c|}{ Cool season } \\
\hline & & $\mathrm{SS}^{\mathrm{z}}$ & $\mathrm{F}$ & $P>\mathrm{F}^{\mathrm{y}}$ & SS & $\mathrm{F}$ & $P>\mathrm{F}$ \\
\hline Sampling & 1 & 56,884 & 103.20 & $<0.01$ & 158,746 & 244.71 & $<0.01$ \\
\hline Concentration (concn) & 1 & 17,293 & 31.37 & $<0.01$ & 1,229 & 1.89 & 0.17 \\
\hline Sampling $\times$ concn & 1 & 2,197 & 3.99 & 0.05 & 3,350 & 5.16 & 0.02 \\
\hline Residual & 56 & 30,868 & & & 36,328 & & \\
\hline
\end{tabular}

${ }^{\mathrm{z}}$ Sequential sum of squares.

y Probability of obtaining an $\mathrm{F}$ this large or larger by chance alone.

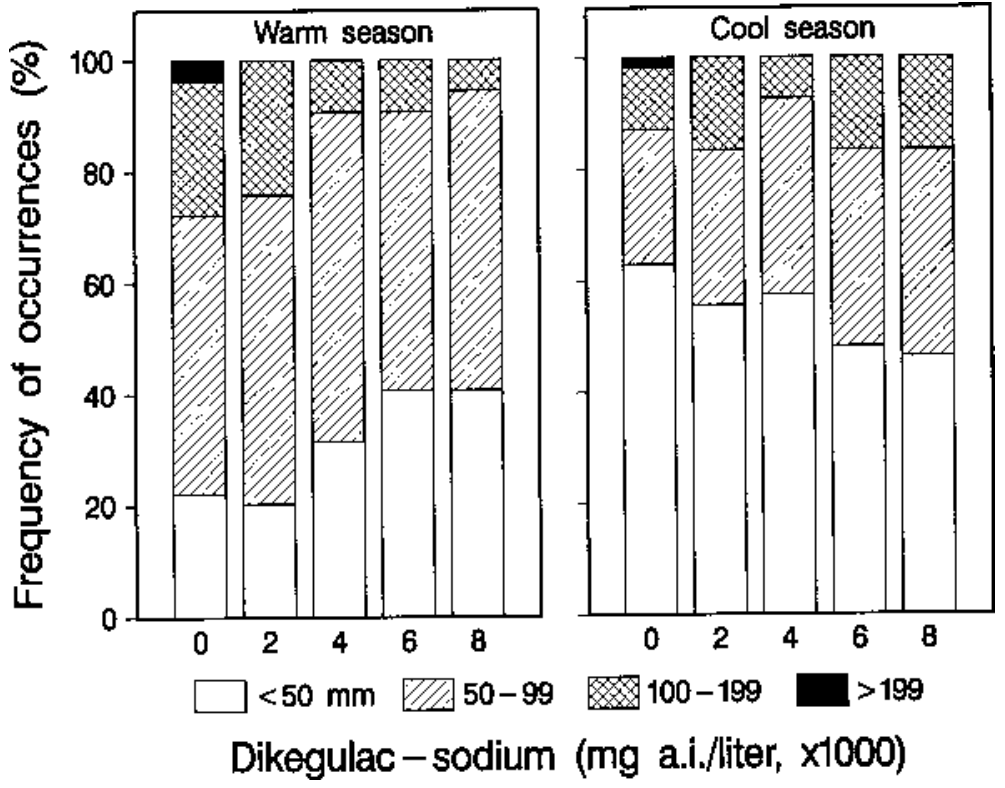

Fig. 2. Frequency distribution of Murraya paniculata lateral shoot length. Dikegulac-sodium at 0, 2000, 4000,6000 , or $8000 \mathrm{mg}$ a.i./liter was sprayed on 6 May (warm season) or $24 \mathrm{Dec}$. (cool season) as the first leaves on newly developing lateral shoots expanded after trimming. Shoots were randomly subsampled 8 weeks later. Each bar represents 54 shoots. 


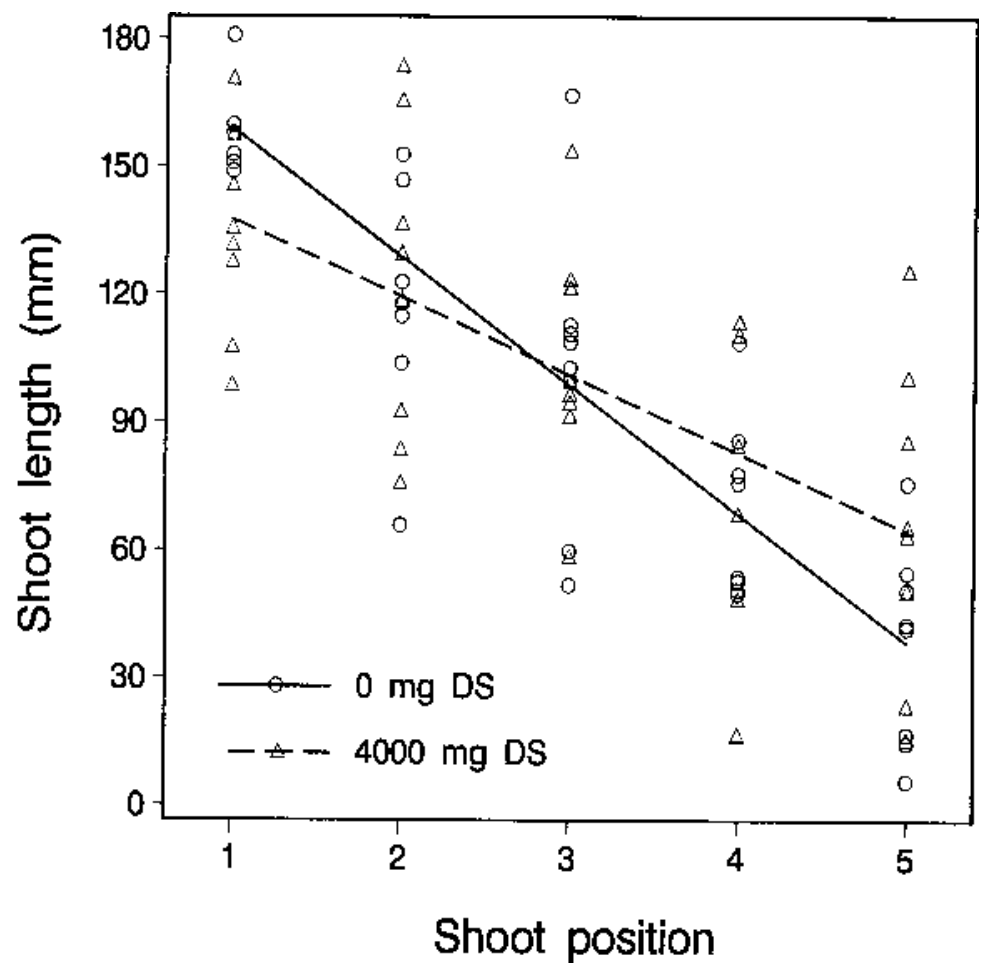

Fig. 3. Lateral shoot elongation of Murraya paniculata seedlings. Seedlings were pruned $0.5 \mathrm{~m}$ above the medium to retain five distal leaves, and the most distal leaves were treated with 0 or $4000 \mathrm{mg}$ a.i. dikegulac-sodium (DS)/liter. The length of newly extending lateral shoot, measured 5 weeks later, was regressed on the shoot position, 1 for the most distal to 5 for the most proximal, and the growth regulator treatment. Shoot length $(\mathrm{mm})=188-30 \times$ position, $0 \mathrm{mg}$ DS; shoot length $=155-18 \times$ position, 4000 mg DS.

Table 2. Analysis of variance for regressing lateral shoot elongation of Murraya paniculata seedlings on growth regulator treatments and the shoot position. Seedlings were pruned $0.5 \mathrm{~m}$ above the medium, lower leaves were removed to retain five distal leaves, and the positions were numbered: 1 for the most distal to 5 for the most proximal leaves. The position 1 leaves were treated with dikegulac-sodium, 0 or $4000 \mathrm{mg}$ a.i./liter, and the length of newly elongating lateral shoots was measured 5 weeks after treatment.

\begin{tabular}{lcrrr}
\hline \hline Source & $\mathrm{df}$ & $\mathrm{SS}^{\mathrm{z}}$ & $\mathrm{F}$ & $P>\mathrm{F}^{\mathrm{y}}$ \\
\hline Treatment & 1 & 206 & 0.25 & 0.62 \\
Position & 1 & 92605 & 113.84 & $<0.01$ \\
Treatment $\times$ position & 1 & 5564 & 6.84 & 0.01 \\
Residual & $74^{\mathrm{x}}$ & 60198 & & \\
\hline
\end{tabular}

${ }^{2}$ Sequential sum of squares.

yrobability of obtaining an $\mathrm{F}$ this large or larger by chance alone.

${ }^{x}$ Degrees of freedom for residual reflects two missing data.

lings. Since DS absorbed by leaves could be translocated to actively growing apical meristems in lateral shoots, it was possible that the growth regulator affected the growth of the fast-growing distal shoots more than slowgrowing proximal shoots, resulting in growth enhancement of lower shoots. In our experiment, the extension reduction of position 1 and 2 shoots was offset by increases of comparable magnitudes in position 4 and 5 shoots, indicating the growth regulator redirected the growth among lateral shoots.

If shoots at position 1 or 2 in the seedling experiment represented the LSL in the hedge experiment and all five shoots represented the SSL, the effects of DS on Murraya are in agreement in both experiments: the growth suppression of long dominant shoots, the enhancement of elongation in short suppressed shoots, and CV reduction. It is likely the negative slopes of the LSL in the hedge experiment were due to suppression of dominant shoot extension, and the trend of less steep slopes for the SSL than for the LSL was due to weakened apical dominance, thus enhancing the extension of suppressed shoots. The difference in the SSL response between two seasons indicates seasonal differences in shoot development (Sachs, 1969).

Sampling shoots as the LSL and SSL in the hedge experiment and measuring shoot length in relation to shoot position in the seedling experiment enabled us to characterize the apical dominance in Murraya hedge regrowth. A DS foliar spray between 4000 and $6000 \mathrm{mg}$ a.i./liter suppressed dominant shoots and enhanced uniform regrowth without causing marked chlorosis or shoot distortion. Characterization of Murraya seasonality and flush growth patterns are needed to determine if the growth regulator spray would result in economic savings.

\section{Literature Cited}

Allen, D.M. and F.B. Cady. 1982. Analyzing experimental data by regression. Lifetime Learning, Belmont, Calif.

Arzee, T.H., H. Langenauer, and J. Gressel. 1977. Effects of dikegulac, a new growth regulator, on apical growth and development of three compositae. Bot. Gaz. 138:18-28.

Bocion, P.F. and W.H. de Silva. 1976. Some effects of dikegulac on the physiology of whole plants and tissues: Interactions with plant hormones, $\mathrm{p}$. 189-198. In: P.E. Pilet (ed.). Plant growth regulation. Springer-Verlag, Berlin.

Bocion, P.F., W.H. de Silva, G.A. Huppi, and W. Szkrybalo. 1975. Group of new chemicals with plant growth regulatory activity. Nature (London) 258:142-144.

Cohen, M.A. 1978. Effects of growth inhibitors on three ornamental species. Scientia Hort. 9:279283.

Criley, R.A. 1980. Landscape maintenance with chemicals, p. 8-24. Second Annu. Orn. Short Course Proc. Res. Ext. Ser. 003. Univ. of Hawaii, Honolulu.

De Silva, W.H., H.R. Graf, and H.R. Walter. 1976. Dikegulac: A novel growth retardant and branching agent for hedges. Proc. 1976 Brit. Crop Protection Conf.-Weeds. p. 349-356.

Martin, G.C. 1987. Apical dominance. HortScience 22:824-933.

Neal, M.C. 1965. In gardens of Hawaii. Bishop Museum Press, Honolulu, Hawaii. p. 480.

Phillips, I.D.J. 1975. Apical dominance. Annu. Rev. Plant Physiol. 26:341-367.

Sachs, R.M. 1969. Growth control in trees-Anatomical and physiological aspects. Intl. Shade Tree Conf. 45:60-78.

Sachs, R.M. and W.P. Hackett. 1972. Chemical inhibition of plant height. HortScience 7:440447.

Sachs, R.M., W.P. Hackett, R.G. Maire, T.M. Kretchun, and J. DeBie. 1970. Chemical control of plant growth in landscapes. Calif. Agr. Expt. Sta. Bul. 844.

Sachs, R.M.,H.Hield, and J.DeBie. 1975. Dikegulac: A promising new foliar-applied growth regulator for woody species. HortScience 10:367369.

Sanderson, K.C. 1977. Research reveals qualities of a new chemical pinching agent for ornamentals. Amer. Nurseryman 146(8):11, 65, 68-71.

SAS Institute. 1990. SAS/STAT user's guide, version 6, 4th ed., v. 2. SAS Inst., Cary, N.C.

Starman, T.W. 1991. Response of Kientzler New Guinea impatiens to manual and chemical pinching. HortScience 26:856-857.

Zilkah, S. and J. Gressel. 1977. Cell culture vs. whole plants for measuring phytotoxicity III. Correlation between phytotoxicities in cell suspension cultures, calli and seedlings. Plant Cell Physiol. 18:815-820. 